\title{
Atypical Multisystem Inflammatory Syndrome in Children (MIS-C)
}

\author{
Suchi Acharya ${ }^{1} \cdot$ Apoorv Saxena $^{1}$ (D) B. M. John ${ }^{1} \cdot$ Vishal Vishnu Tewari $^{2}$
}

Received: 23 February 2021 / Accepted: 12 April 2021 / Published online: 1 May 2021

(C) Dr. K C Chaudhuri Foundation 2021

To the Editor: Severe acute respiratory syndrome coronavirus 2 (SARS-CoV-2) is associated with several hyperinflammatory conditions, some of which include children presenting with Kawasaki-like disease. This has been termed 'multisystem inflammatory syndrome in children' (MIS-C) [1]. We report a case of a 6-y-old child with an atypical presentation of MIS-C.

This previously healthy boy was admitted with intermittent fever of $10 \mathrm{~d}$ duration and erythema multiforme like rash initially involving both legs and subsequently spreading over whole body, however sparing the face and mucosa. On admission, he was hemodynamically stable and systemic examination was normal. He became afebrile within $24 \mathrm{~h}$ of admission on symptomatic therapy. His initial workup revealed RT-PCR positive for SARS-CoV-2, anemia ( $\mathrm{Hb} 9.1 \mathrm{~g} / \mathrm{dL}$ ), neutrophilic leucocytosis $(15,600 /$ cumm, $p$ 79\%), thrombocytosis (6.3 lacs/cumm) and elevated D-dimer $(1074 \mathrm{ng} / \mathrm{mL})$; however, other markers of inflammation like erythrocyte sedimentation rate (ESR), C-reactive protein (CRP) and serum ferritin were normal. The echocardiography showed left main coronary artery dilatation (z score + 3.6). He was diagnosed as a case of MIS-C according to Centre for Disease Control and Prevention (CDC) criteria [2]. He was managed with intravenous immunoglobulins (IVIG) at $2 \mathrm{~g} / \mathrm{kg}$ and low-dose aspirin with complete recovery over next $12 \mathrm{wk}$.

MIS-C is a clinicopathologic condition encompassing a spectrum, which mimics complete or incomplete Kawasaki disease (KD), toxic shock syndrome, hemophagocytic lymphohistiocytosis and/or macrophage activation syndrome [3]. Few MIS-C patients even without KD-like symptoms also developed coronary artery aneurysm [4].

Apoorv Saxena

apoorv_saxena19@yahoo.com

1 Department of Pediatrics, Armed Forces Medical College, Pune, Maharashtra 411040, India

2 Department of Pediatrics, Command Hospital (Southern Command) $\&$ Armed Forces Medical College, Pune, Maharashtra, India
Our case was atypical since the child had become afebrile within $24 \mathrm{~h}$ of admission and did not have elevated markers of inflammation except D-dimer. In the pre-COVID scenario, in the absence of D-dimer testing, the child would not have been subjected to echocardiography. Further, the child had coronary artery changes even in the absence of evidence of significant hyperinflammation thus highlighting the importance of keeping a low threshold for cardiac evaluation in the current scenario.

\section{Declarations}

Conflict of Interest None.

\section{References}

1. Castagnoli R, Votto M, Licari A, et al. Severe acute respiratory syndrome coronavirus 2 (SARS-CoV-2) infection in children and adolescents: a systematic review. JAMA Pediatr. 2020 April 22 (Epub ahead of print).

2. Centers for Disease Control and Prevention. Emergency preparedness and response: health alert network. Published May 14, 2020. Health advisory https://emergency.cdc.gov/han/2020/han00432.asp. Accessed 9 Jan 2021.

3. Riphagen S, Gomez X, Gonzalez-Martinez C, Wilkinson N, Theocharis P. Hyperinflammatory shock in children during COVID-19 pandemic. Lancet. 2020;395:1607-8.

4. Feldstein LR, Rose EB, Horwitz SM, et al. Multisystem inflammatory syndrome in US children and adolescents. N Engl J Med. 2020;383:334-46.

Publisher's Note Springer Nature remains neutral with regard to jurisdictional claims in published maps and institutional affiliations. 